\title{
Asia Pacific TAVI registry (an APSIC initiative): initial report of early outcomes
}

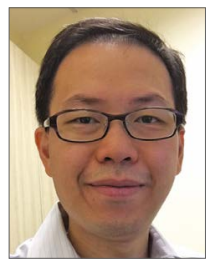

\section{Edgar Tay ${ }^{1,2}$, MBBS, MRCP (UK), MMed (Int Med), FAMS, FACC, FESC;}

Thet Khaing ${ }^{1 *}$, MBBS, MRCP (UK); Wei Hsian Yin³ ${ }^{3}$ MD; Enrique Fabio Posas ${ }^{4}$, MD;

Paul Hsien-Li Kao ${ }^{5}$, MD; Wacin Buddhari ${ }^{6}, \mathrm{MD}$; Kentaro Hayashida ${ }^{7}, \mathrm{MD}, \mathrm{PhD}$;

Kay Woon $\mathrm{Ho}^{8,9}$, MBBS, MRCP (UK), MMed (Int Med); Mao Shin Lin ${ }^{5}$, MD;

Jonathan Yap 9 , MBBS, MRCP, MMed (Int Med), MPH, GDip (Pall Med); Jun Jie Zhang ${ }^{10}$, MD;

Paul Tonn Lim Chiam ${ }^{11}$, MBBS, MRCP, MMed (Int Med), FRCP; Mohd Ali Rosli ${ }^{12}$, MD;

Seung-Jung Park ${ }^{13}$, MD; Wasan Udayacherm ${ }^{14}$, MD; Ryo Yanagisawa ${ }^{7}, \mathrm{MD}$;

Huay Cheem Tan ${ }^{1,2}$, MBBS, MRCP; Michael K.Y. Lee ${ }^{15}$, MD

1. Cardiology Department, National University Heart Centre, Singapore, Singapore; 2. National University Singapore,

Singapore; 3. Division of Cardiology, Heart Center, Cheng-Hsin General Hospital, and School of Medicine, National Yang-Ming

University, Taipei, Taiwan; 4. St. Luke's Heart Institute, Taguig, Philippines; 5. Department of Internal Medicine, National

Taiwan University Hospital, Taipei, Taiwan; 6. Division of Cardiovascular Medicine, Chulalongkorn University, Bangkok,

Thailand; 7. Department of Cardiology, School of Medicine, Keio University, Tokyo, Japan; 8. Duke-NUS Medical School,

Singapore; 9. National Heart Centre Singapore, Singapore; 10. Nanjing Medical University, Nanjing, China; 11. Mt Elizabeth

Hospital, Singapore; 12. Cardiac Vascular Sentral, Kuala Lumpur, Malaysia; 13. Asan Medical Centre, Seoul, South Korea;

14. King Chulalongkorn Hospital, Bangkok, Thailand; 15. Queen Elizabeth Hospital, Kowloon, Hong Kong, China

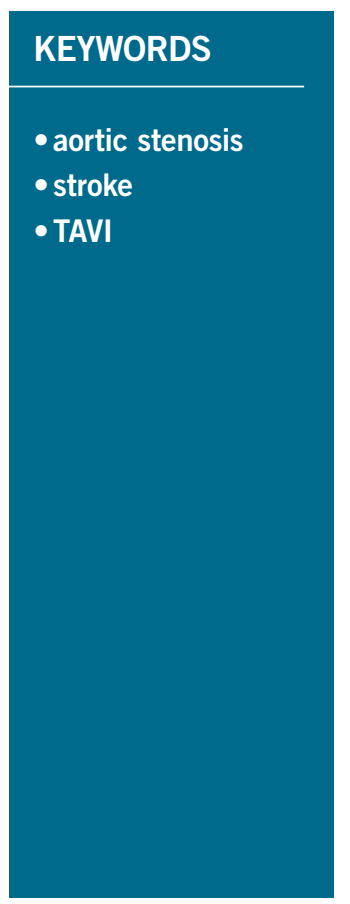

Abstract

Aims: The aim of the study was to report the clinical experience, 30-day mortality and acute outcomes of patients undergoing transcatheter aortic valve implantation (TAVI) in the Asia Pacific region.

Methods and results: The Asia Pacific TAVI registry is an international, multicentre, prospective, observational registry managed under the auspices of the Asian Pacific Society of Interventional Cardiology (APSIC). Patients undergoing TAVI in seven centres from Hong Kong, Japan, Philippines, Singapore and Taiwan, treated with TAVI devices for severe symptomatic aortic stenosis, were assessed. This first review presents the acute results and 30-day mortality. A multivariable analysis was also performed to identify independent predictors of early all-cause mortality. The enrolment was from 2009 to 2017 and a total of 1,125 patients were recruited. The 30-day mortality rate was $2.5 \%$. Baseline logistic EuroSCORE more than 16 was independently associated with a 2.8 -times increased risk of 30-day all-cause mortality $(\mathrm{p}=0.016)$. Post-procedural stroke (HR 4.9, $\mathrm{p}=0.008$ ) was also associated with increased mortality.

Conclusions: This initial report of the Asia Pacific TAVI registry demonstrated good acute success and low 30-day mortality. The preprocedural logistic EuroSCORE and post-procedural stroke incidence were strongly associated with acute mortality. Further attempts to reduce post-procedural stroke should be explored.

\footnotetext{
*Corresponding author: National University Heart Centre, 5 Lower Kent Ridge Rd, Singapore 119074. E-mail: thet.khaingdr@gmail.com
} 


\section{Abbreviations}

AKI acute kidney injury

APSIC Asian Pacific Society of Interventional Cardiology

AS aortic stenosis

ASE American Society of Echocardiography

CABG coronary artery bypass graft

CVA cerebrovascular accident

ESRD end-stage renal disease

gSEM generalised structural equation model

NUHCS National University Heart Centre Singapore

NYHA New York Heart Association

PCI percutaneous coronary intervention

PPM permanent pacemaker

SAVR surgical aortic valve replacement

STS Society of Thoracic Surgeons

TAVI transcatheter aortic valve implantation

TVT transcatheter valve therapy

VARC Valve Academic Research Consortium

\section{Introduction}

The Asian population is growing and nearly four billion people live in Asia. Health care in Asia has been evolving rapidly over the last few decades and is influencing the life expectancy of its population. In fact, contemporary data indicate that the ageing population in Asia is growing as much as its economy (Figure 1)'. This suggests that aortic valve stenosis rates may also increase over time. Although transcatheter aortic valve implantation (TAVI) has been demonstrated clearly to be an effective treatment in severe aortic stenosis (AS) patients at intermediate to high risk for surgical aortic valve replacement (SAVR), uptake of the TAVI procedure in Asia compared with its population is $l^{2-4}$. This therapy, however, is anticipated to grow substantially in the coming years. The Asian Pacific Society of Interventional Cardiology (APSIC) supported the establishment of this registry to chart prospectively the outcomes and uptake of TAVI in the Asia Pacific region.

\section{Editorial, see page 15}

\section{Methods}

The current Asia Pacific registry includes 14 centres and recruitment is ongoing. This current analysis includes data from seven sites in Hong Kong, Japan, Philippines, Singapore and Taiwan. The procedures were carried out between 2009 and 2017. Data were collected from each study site and then sent via web-based case report forms (CRF) to the National University Heart Centre Singapore (NUHCS) Cardiovascular Research Institute for collation and analysis. The ethics committees of the participating centres approved data collection. At some sites, patients' informed consents were collected. Patient selection, procedure protocol and post-procedural care were performed according to local practice.

\section{DATA AND DEFINITIONS}

Preoperative baseline and outcome data were collected based on a uniform reporting template (CRF) and standardised definitions.

Postoperative outcomes were defined according to the updated Valve Academic Research Consortium (VARC-2) definitions ${ }^{5}$. The 30-day postoperative mortality is defined as all deaths that occurred within 30 days from the procedure.

The echocardiographic measurements were carried out according to the American Society of Echocardiography (ASE) guidelines ${ }^{6,7}$.

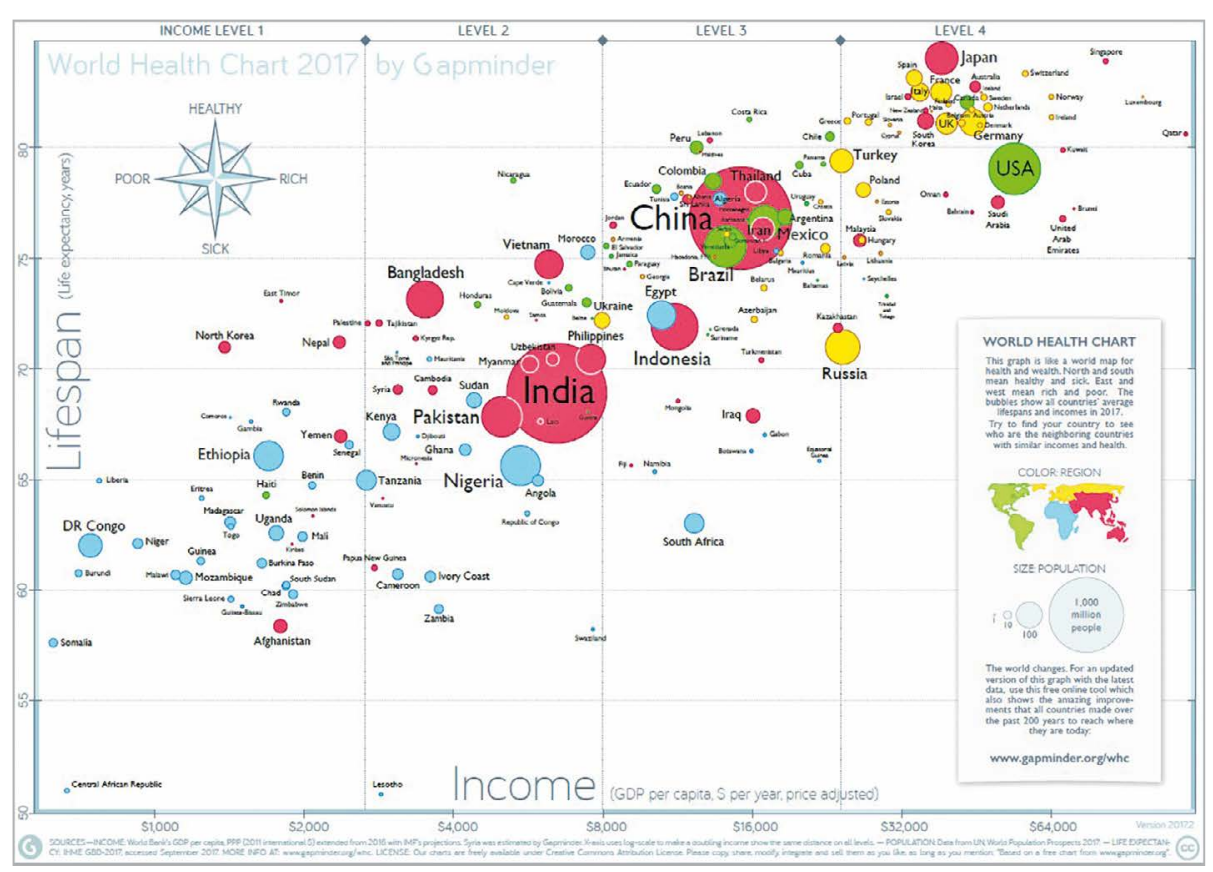

Figure 1. World Health Chart. 


\section{STATISTICAL ANALYSIS}

Data are presented as frequency/percentages and mean \pm standard deviation, depending on the nature of the data. Confirmatory analysis of 30-day mortality was performed with logistic regression in the context of a generalised structural equation model (gSEM). The advantage of using the gSEM framework was that both analyses could be performed in one single framework. A backward elimination procedure (removal $\mathrm{p}>0.05$ ) was also incorporated for model selection. Analyses were performed using Stata MP version 14 (StataCorp, College Station, TX, USA); all statistical tests were conducted at a $5 \%$ level of significance.

\section{Results \\ STUDY POPULATION}

The study population comprises 1,125 patients enrolled from February 2009 to December 2017. Mean age was 79.9 \pm 8.1 years; $48.5 \%$ were male. Mean logistic EuroSCORE was 20.4 \pm 16.7 ; mean Society of Thoracic Surgeons (STS) score was 7.1 \pm 6.2 . The New York Heart Association (NYHA) functional class was I (12.6\%), II (36.3\%), III (40.7\%) and IV (10.2\%). Preoperative clinical variables of the patients are listed in Table 1.

\section{BASELINE ECHOCARDIOGRAPHIC PARAMETERS}

All the patients underwent preoperative echocardiographic examination and baseline data were collected. The mean baseline transaortic gradient was $50.7 \pm 20.8 \mathrm{mmHg}$ and the aortic valve area $0.83 \pm 0.57 \mathrm{~cm}^{2}$. There were 32 patients $(2.8 \%)$ with concomitant severe aortic regurgitation and 68 patients $(6 \%)$ had a bicuspid aortic valve. The mean left ventricular ejection fraction (LVEF) was $50.7 \pm 15 \%$ and a significant percentage $(34.8 \%$ ) had pulmonary hypertension based on echocardiographic measurement of pulmonary artery systolic pressure (PASP). Preoperative baseline echocardiographic data are listed in Table 1.

\section{PROCEDURE DATA}

The access routes included transfemoral, 910 (80.9\%), transaortic, $11(1 \%)$ and trans-subclavian, $6(0.5 \%)$. The remaining $72(6.4 \%)$ were performed via the transapical access. The most common valve platform used was the balloon-expandable valve and the most commonly used valve size was $26 \mathrm{~mm}$. The post-procedure mean transaortic pressure gradient was $10.7 \pm 7.0 \mathrm{mmHg}$, while the mean post-procedure aortic valve area improved significantly $\left(1.7 \pm 0.4 \mathrm{~cm}^{2}\right)$. In this registry, $70.5 \%$ received first-generation TAVI devices and $29.5 \%$ received later-generation TAVI devices. The 30-day mortality rate of first-generation devices was $3.5 \%$ and that of later-generation devices was $1.1 \%$.

\section{THIRTY-DAY MORTALITY}

All cause 30 -day mortality was $2.5 \%$. The causes of 30 -day mortality are listed in Figure 2. The most common cause of death was cardiovascular $(71.4 \%)$. The majority of the patients $(68 \%)$ had a history of ischaemic heart disease, and $32 \%$ had a history of cerebrovascular accident. Based on the postoperative echocardiography,

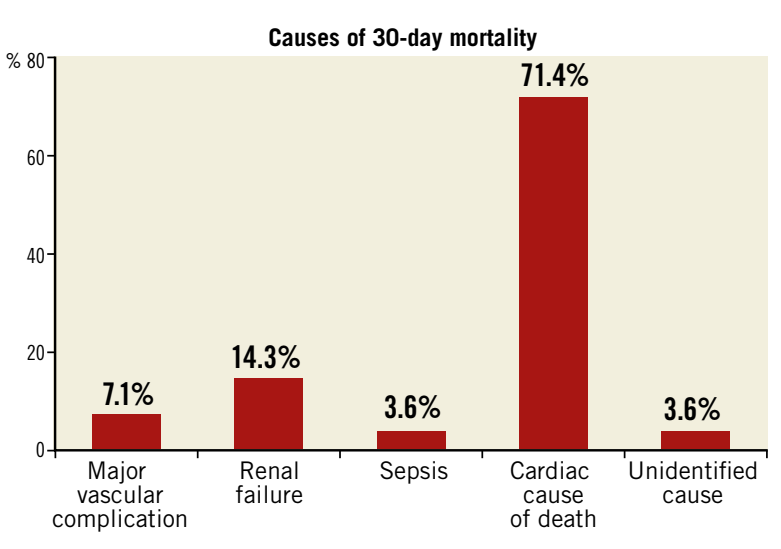

Figure 2. Causes of 30-day mortality.

$17 \%$ of patients had moderate paravalvular regurgitation and $7 \%$ had mild paravalvular regurgitation. Based on the timeline, we also arbitrarily divided mortality outcomes into two groups, TAVI before 2014 and TAVI after 2014. The 30-day mortality before 2014 was $4.7 \%$ and it improved to $1.9 \%$ after 2014 .

\section{ACUTE PROCEDURAL OUTCOME}

The 30-day outcomes of acute kidney injury (AKI), stroke, major vascular complications and major bleeding, defined according to VARC-2, are presented in Figure 3. In this registry, AKI occurred in 77 patients $(6.8 \%)$. In fact, AKI was the most common complication, followed by major vascular complications $(5.8 \%, n=65)$. Stroke occurred in 14 patients $(1.2 \%)$ and one-year mortality in stroke patients was high $(35 \%, \mathrm{n}=5)$. The permanent pacemaker (PPM) implantation rate at 30 days was $10.6 \%(n=119)$. Paravalvular regurgitation after TAVI was trivial in 135 patients $(12.0 \%)$, mild in $184(16.4 \%)$, moderate in $74(6.6 \%)$ and severe in 1 patient $(0.1 \%)$. There was $0.58 \%, 0.67 \%$ and $0.85 \%$ of coronary occlusion, aortic root rupture and emergency valve-in-valve, respectively. In this registry, the rate of major vascular complications from transfemoral access was $4.9 \%$ and from other access sites was $11.2 \%$.

\section{ONE-YEAR ALL-CAUSE MORTALITY}

The one-year all-cause mortality rate among the post-TAVI patients was $8.8 \%$.

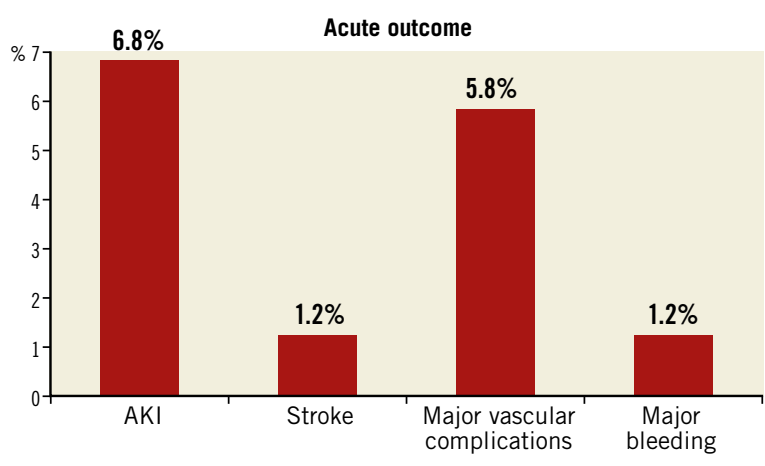

Figure 3. Acute outcomes of post-TAVI patients. 
Table 1. Baseline characteristics, echocardiographic and procedure data.

\begin{tabular}{|c|c|c|}
\hline \multicolumn{2}{|c|}{ Baseline characteristics } & Mean $\pm S D / n(\%)$ \\
\hline \multicolumn{2}{|l|}{ Age, years } & $79.9 \pm 8.1$ \\
\hline \multicolumn{2}{|l|}{ Male gender } & $546(48.5)$ \\
\hline \multicolumn{2}{|l|}{ Female gender } & $579(51.5)$ \\
\hline \multicolumn{2}{|l|}{ STS score, \% } & $7.1 \pm 6.2$ \\
\hline \multicolumn{2}{|c|}{ STS score less than 4} & $297(26.4)$ \\
\hline \multicolumn{2}{|c|}{ Logistic EuroSCORE, \% } & $20.4 \pm 16.7$ \\
\hline \multirow{4}{*}{$\begin{array}{l}\text { NYHA functiona } \\
\text { class }\end{array}$} & I & $142(12.6)$ \\
\hline & II & $408(36.3)$ \\
\hline & III & $458(40.7)$ \\
\hline & IV & $115(10.2)$ \\
\hline \multicolumn{2}{|c|}{ Coronary artery disease } & $617(54.8)$ \\
\hline \multicolumn{2}{|l|}{ Previous CABG } & $144(12.8)$ \\
\hline \multicolumn{2}{|l|}{ Previous PCl } & $373(33.2)$ \\
\hline \multicolumn{2}{|c|}{ Previous valve surgery } & $61(5.4)$ \\
\hline \multicolumn{2}{|c|}{ Cerebral vascular disease } & $123(10.9)$ \\
\hline \multicolumn{2}{|c|}{ Peripheral arterial disease } & $266(23.6)$ \\
\hline \multicolumn{2}{|c|}{ Chronic pulmonary disease } & $315(28)$ \\
\hline \multicolumn{2}{|c|}{ Diabetes mellitus } & 415 (36.9) \\
\hline \multicolumn{2}{|l|}{ Hypertension } & $866(77)$ \\
\hline \multicolumn{2}{|l|}{ Hyperlipidaemia } & $679(60.4)$ \\
\hline \multicolumn{2}{|c|}{ Chronic kidney disease } & $535(47.6)$ \\
\hline \multicolumn{2}{|l|}{ ESRD } & $68(6)$ \\
\hline \multicolumn{3}{|c|}{ Echocardiographic data } \\
\hline \multicolumn{2}{|c|}{ Aortic valve area, $\mathrm{cm}^{2}$} & $0.83 \pm 0.57$ \\
\hline \multicolumn{2}{|c|}{ Mean pressure gradient, $\mathrm{mmHg}$} & $50.7 \pm 20.8$ \\
\hline \multicolumn{2}{|c|}{ Bicuspid aortic valve } & $68(6)$ \\
\hline \multicolumn{2}{|l|}{ LVEF, \% } & $56 \pm 15$ \\
\hline \multirow{5}{*}{$\begin{array}{l}\text { Degree of aortic } \\
\text { regurgitation }\end{array}$} & None & $86(7.6)$ \\
\hline & Trivial & $149(13.2)$ \\
\hline & Mild & $454(40.4)$ \\
\hline & Moderate & $187(16.6)$ \\
\hline & Severe & $32(2.8)$ \\
\hline
\end{tabular}

Echocardiographic data

Pulmonary hypertension

Number of patients who reached one-year follow-up

$392(34.8)$

Procedure data

\begin{tabular}{|l|l|c|}
\hline \multirow{2}{*}{$\begin{array}{l}\text { Implanta- } \\
\text { tion } \\
\text { approach }\end{array}$} & Transfemoral access & $910(91.1)$ \\
\cline { 2 - 3 } & Transapical access & $72(7.2)$ \\
\cline { 2 - 3 } & Transaortic access & $11(1.1)$ \\
\cline { 2 - 3 } & Trans-subclavian & $6(0.6)$
\end{tabular}

Valve size, $\mathrm{mm}$

\begin{tabular}{|l|c|}
\hline 20 & $12(1.1)$ \\
\hline 21 & $4(0.4)$ \\
\hline 23 & $343(30.5)$ \\
\hline 25 & $27(2.4)$ \\
\hline 26 & $379(33.7)$ \\
\hline 27 & $25(2.2)$ \\
\hline 29 & $222(19.7)$ \\
\hline 31 & $40(3.6)$ \\
\hline 34 & $8(0.7)$ \\
\hline Valve ID & $219(19.5)$ \\
\hline CoreValve & $148(13.2)$ \\
\hline Evolut R & $46(4.1)$ \\
\hline Lotus & $26(2.3)$ \\
\hline Portico & $290(25.8)$ \\
\hline SAPIEN XT & $90(8.0)$ \\
\hline SAPIEN 3 & 57 (5.1) \\
\hline SAPIEN & \\
\hline $\begin{array}{l}\text { Missing data for aortic regurgitation 217 (19.3\%), implantation } \\
\text { approach 126 (11.2\%), valve ID 249 (22\%) and valve size 66 (5.8\%). } \\
\text { CABG: coronary artery bypass graft; ESRD: end-stage renal disease; } \\
\text { LVEF: left ventricular ejection fraction; NYHA: New York Heart } \\
\text { Association; PCl: percutaneous coronary intervention; STS: Society of } \\
\text { Thoracic Surgeons }\end{array}$ \\
\hline
\end{tabular}

be increased by 9.2 times $(\mathrm{p}=0.008)$. However, preprocedural CVA was not significantly associated with the occurrence of post-procedural CVA (odds ratio [OR] 1.6, $\mathrm{p}=0.546$ ). There were only two patients who suffered from preprocedural and post-procedural CVA.

\section{Discussion}

This is the first report of the APSIC-sponsored TAVI registry. In summary, we found that acute procedural success in this intermediate to high surgical risk cohort was good. There were reasonably low mortality rates and acceptable complication rates. Importantly, it demonstrated that both the logistic EuroSCORE and STS scores were independent predictors of mortality pre procedure, while cerebrovascular events were independent procedure-related predictors of morbidity and mortality. In this registry, the majority of the patients were female. Even though there have been concerns about the small annulus size in the Asian population, in this registry more than $65 \%$ of patients required valve sizes of $26 \mathrm{~mm}$ or larger. 
In this registry, the proportion of bicuspid aortic valve patients (6\%) is lower compared to other Asian sites (e.g., China TAVI registries). This may be related to the average age of this cohort of patients (mean 79 years). It is speculated that the increased number of bicuspid valve patients in the Chinese cohorts may be due to the recruitment of younger patients in their study.

\section{COMPARISON TO OTHER PUBLISHED REGISTRIES}

This registry is supported and endorsed by the APSIC. This is an important publication which cements the role that APSIC plays in promoting collaborative research.

There are currently two published Asian registries. These are the Asian TAVI registry followed by the Japanese OCEAN-TAVI registry ${ }^{8,9}$. The unique difference is that this registry will continue to recruit patients from North and also South-East Asian patients. Also, this means that collectively it includes patients who are of more heterogenous ethnicity as well as incorporating varied implant volumes and experience. The early outcomes published in this study are not significantly different from the other two Asian studies thus far. In the patients recruited in this study, mostly second-generation TAVI devices (e.g., SAPIEN XT [Edwards Lifesciences, Irvine, CA, USA] and CoreValve ${ }^{\circledR}$ [Medtronic, Minneapolis, MN, USA]) were utilised, and in only a few patients were very early generation devices utilised. There were also some third-generation devices (Evolut ${ }^{\mathrm{TM}} \mathrm{R}$ [Medtronic], SAPIEN 3 [Edwards Lifesciences], Lotus ${ }^{\mathrm{TM}}$ [Boston Scientific, Marlborough, MA, USA]) used. The patients included were mostly intermediate- to high-risk patients. The low 30-day mortality rates should therefore be compared to more contemporary studies utilising the appropriate generation of devices. Figure 4 shows that the outcomes compare favourably to other studies with relatively similar baseline risk profiles ${ }^{9-13}$.

\section{ROLE OF THE LOGISTIC EUROSCORE OR STS SCORE}

There are currently several risk scores being utilised for patients undergoing TAVI. These include the STS/American College of Cardiology (ACC) transcatheter valve therapy (TVT) mortality risk score, EuroSCORE I, EuroSCORE II, STS PROM and German AV score ${ }^{14}$. These scores serve several purposes, two of which are especially important. The first is to predict the 30-day mortality of patients undergoing surgery or TAVI and the second is the ability to compare across other studies. In this study, the traditional logistic EuroSCORE as well as the STS score were utilised to enable comparison across registries. While the logistic EuroSCORE and EuroSCORE II have been validated, with the latter being superior in Chinese patients for valve surgery or coronary artery bypass graft (CABG) surgery, these have not been validated in TAVI patients. This study showed that a logistic EuroSCORE of $>16$ and STS score $>8$ could predict mortality in this group of Asian TAVI patients. In the absence of other validated scoring systems, this may be utilised as a preprocedural predictor for contemporary practice.

\section{IMPACT OF STROKE}

Stroke in this study occurred infrequently $(1.2 \%)$. It is important to point out that this refers to clinically evident stroke and site-reported stroke. Thus, the true incidence may be higher. It is well established that systematic neurological evaluation by trained neurologists may detect a higher incidence of stroke post TAVI. Despite the low incidence of stroke, the impact of stroke on 30-day mortality is striking. Prior studies have also demonstrated that stroke after TAVI can be devastating. A German study showed a fivefold increase in the 30-day mortality after post-TAVI stroke ${ }^{15}$. These results mandate that the Asia Pacific TAVI community should focus future attention on this complication. This would require a more in-depth assessment of risks for stroke and assessment of the impact of cerebral protection devices in the Asia Pacific cohort of patients.

\section{Limitations}

Although standardised reporting was encouraged, techniques and choices of valve were left to the discretion of individual sites. The clinical outcomes were not independently adjudicated, and echocardiographic reporting was not evaluated by a core laboratory. This may have introduced bias into the study. However, the hard

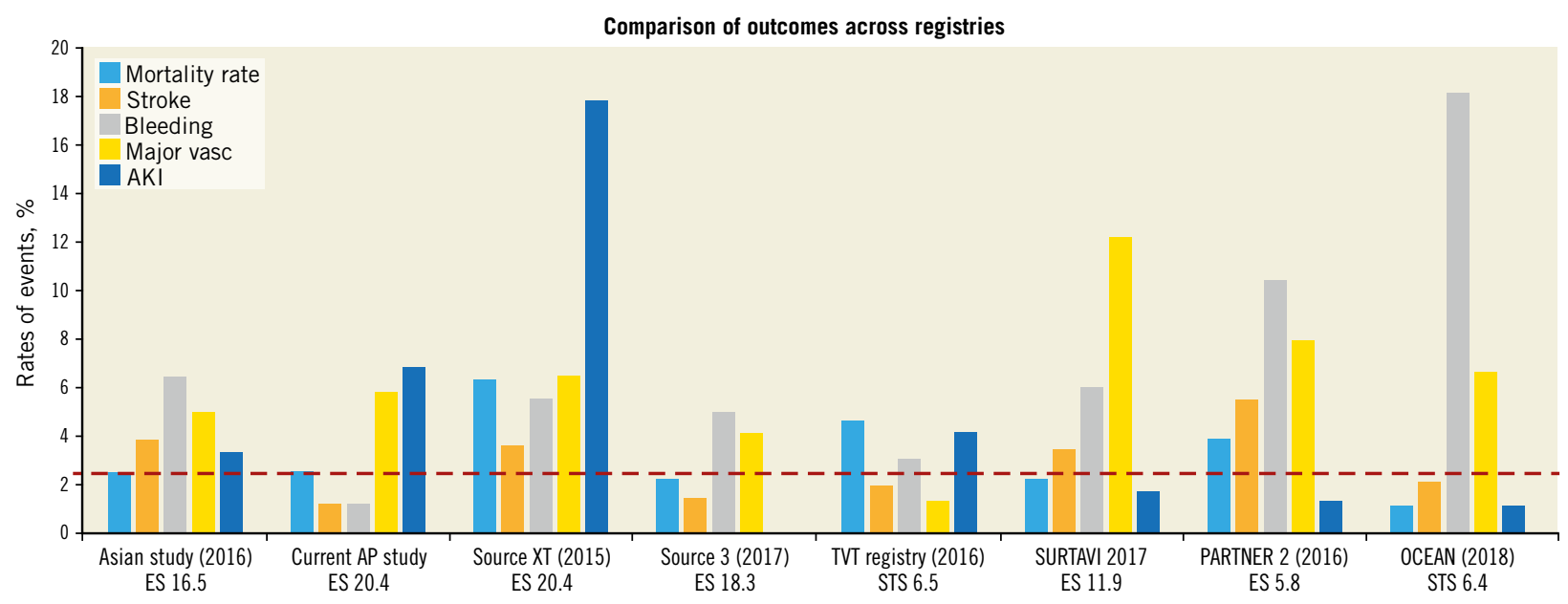

Figure 4. Comparison of outcomes across registries ${ }^{13}$. 
outcome of mortality is reasonably robust given that the current sites have a systematic mechanism for 30-day follow-up.

\section{Conclusions}

This initial report of the APSIC-supported Asia Pacific TAVI registry demonstrates that the 30-day outcomes were good. A high logistic EuroSCORE and high STS scores pre procedure, as well as postprocedure stroke are associated with increased 30-day mortality.

\section{Impact on daily practice}

One of the important messages from this registry is the stroke risk in post-TAVI patients which can have a serious impact on 30-day mortality and morbidity. For the Asian population, stroke risk assessment before the procedure is crucially important based on this early report of the Asia Pacific TAVI registry.

\section{Conflict of interest statement}

The authors have no conflicts of interest to declare.

\section{References}

1. Rosling H. Factfulness. First edition. New York, NY, USA: Flatiron Books; 2018.

2. Otto CM, Kumbhani DJ, Alexander KP, Calhoon JH, Desai MY, Kaul S, Lee JC, Ruiz CE, Vassileva CM. ACC Expert Consensus Decision Pathway for Transcatheter Aortic Valve Replacement in the Management of Adults With Aortic Stenosis: A Report of the American College of Cardiology Task Force on Clinical Expert Consensus Documents. J Am Coll Cardiol. 2017;69:1313-46.

3. Cesna S, De Backer O, Søndergaard L. Rapid adoption of transcatheter aortic valve replacement in intermediate- and high-risk patients to treat severe aortic valve stenosis. J Thorac Cardiovasc Surg. 2017;9:1432-6.

4. Hon JKF, Tay E. Transcatheter aortic valve implantation in Asia. Ann Thorac Cardiovasc Surg. 2017;6:504-9.

5. Kappetein AP, Head SJ, Généreux P, Piazza N, van Mieghem NM, Blackstone EH, Brott TG, Cohen DJ, Cutlip DE, van Es GA, Hahn RT, Kirtane AJ, Krucoff MW, Kodali S, Mack MJ, Mehran R, Rodés-Cabau J, Vranckx P, Webb JG, Windecker S, Serruys PW, Leon MB. Updated standardized endpoint definitions for transcatheter aortic valve implantation: the Valve Academic Research Consortium-2 consensus document. Eur Heart J. 2012;33:2403-18. 6. Baumgartner H, Hung J, Bermejo J, Chambers JB, Edvardsen T, Goldstein S, Lancellotti P, LeFevre M, Miller F Jr, Otto CM. Recommendations on the Echocardiographic Assessment of Aortic Valve Stenosis: A Focused Update from the European Association of Cardiovascular Imaging and the American Society of Echocardiography. J Am Soc Echocardiogr. 2017;30:372-92.

7. Zamorano JL, Badano LP, Bruce C, Chan KL, Gonçalves A, Hahn RT, Keane MG, La Canna G, Monaghan MJ, Nihoyannopoulos P, Silvestry FE, Vanoverschelde JL, Gillam LD. EAE/ASE recommendations for the use of echocardiography in new transcatheter interventions for valvular heart disease. Eur Heart J. 2011;32:2189-214.
8. Yoon SH, Ahn JM, Hayashida K, Watanabe Y, Shirai S, Kao HL, Yin WH, Lee MK, Tay E, Araki M, Yamanaka F, Arai T, Lin MS, Park JB, Park DW, Kang SJ, Lee SW, Kim YH, Lee CW, Park SW, Muramatsu T, Hanyu M, Kozuma K, Kim HS, Saito S, Park SJ; Asian TAVR Investigators. Clinical Outcomes Following Transcatheter Aortic Valve Replacement in Asian Population. JACC Cardiovasc Interv. 2016;9:926-33.

9. Hosoba S, Yamamoto M, Shioda K, Sago M, Koyama Y, Shimura T, Kagase A, Tada N, Naganuma T, Araki M, Yamanaka F, Shirai S, Watanabe Y, Hayashida K. Safety and efficacy of minimalist approach in transfemoral transcatheter aortic valve replacement: insights from the Optimized transCathEter vAlvular interventioN-Transcatheter Aortic Valve Implantation (OCEANTAVI) registry. Interact Cardiovasc Thorac Surg. 2018;26:420-4. 10. Wendler O, Schymik G, Treede H, Baumgartner H, Dumonteil N, Ihlberg L, Neumann FJ, Tarantini G, Zamarano JL, Vahanian A. SOURCE 3 Registry: Design and 30-Day Results of the European Postapproval Registry of the Latest Generation of the SAPIEN 3 Transcatheter Heart Valve. Circulation. 2017;135:1123-32.

11. Reardon MJ, Van Mieghem NM, Popma JJ, Kleiman NS, Søndergaard L, Mumtaz M, Adams DH, Deeb GM, Maini B, Gada H, Chetcuti S, Gleason T, Heiser J, Lange R, Merhi W, Oh JK, Olsen PS, Piazza N, Williams M, Windecker S, Yakubov SJ, Grube E, Makkar R, Lee JS, Conte J, Vang E, Nguyen H, Chang Y, Mugglin AS, Serruys PW, Kappetein AP; SURTAVI Investigators. Surgical or Transcatheter Aortic-Valve Replacement in Intermediate-Risk Patients. N Engl J Med. 2017;376:1321-31.

12. Grover FL, Vemulapalli S, Carroll JD, Edwards FH, Mack MJ, Thourani VH, Brindis RG, Shahian DM, Ruiz CE, Jacobs JP, Hanzel G, Bavaria JE, Tuzcu EM, Peterson ED, Fitzgerald S, Kourtis M, Michaels J, Christensen B, Seward WF, Hewitt K, Holmes DR Jr; STS/ACC TVT Registry. 2016 Annual Report of The Society of Thoracic Surgeons/American College of Cardiology Transcatheter Valve Therapy Registry. J Am Coll Cardiol. 2016;69: 1215-30.

13. Schymik G, Lefèvre T, Bartorelli AL, Rubino P, Treede H, Walther T, Baumgartner H, Windecker S, Wendler O, Urban P, Mandinov L, Thomas M, Vahanian A. European experience with the second-generation Edwards SAPIEN XT transcatheter heart valve in patients with severe aortic stenosis: 1-year outcomes from the SOURCE XT Registry. JACC Cardiovasc Interv. 2015;8: 657-69.

14. Arsalan M, Weferling M, Hecker F, Filardo G, Kim WK, Pollock BD, Van Linden A, Arsalan-Werner A, Renker M, Doss M, Kalbas S, Hamm CW, Liebetrau C, Mack MJ, Walther T. TAVI risk scoring using established versus new scoring systems: role of the new STS/ACC model. EuroIntervention. 2018;13:1520-6.

15. Werner N, Zeymer U, Schneider S, Bauer T, Gerckens U, Linke A, Hamm C, Sievert H, Eggebrecht H, Zahn R; German Transcatheter Aortic Valve Interventions-Registry Investigators. Incidence and Clinical Impact of Stroke Complicating Transcatheter Aortic Valve Implantation: Results from the German TAVI Registry. Catheter Cardiovasc Interv. 2016;88:644-53. 